\title{
Reasonable Adjustments in Assessment: Putting Law and Policy into Practice in Australia
}

Joy Cumming ${ }^{\mathrm{a} *}$, Elizabeth Dickson $^{\mathrm{b}}$ and Amanda Webster ${ }^{\mathrm{c}}$

${ }^{a}$ Griffith Institute for Educational Research, Griffith University, Brisbane, QLD, Australia;

${ }^{b}$ Faculty of Law, Queensland University of Technology, Brisbane, QLD, Australia; ${ }^{c}$ School of Education and Professional Studies, Griffith University, Brisbane, QLD, Australia

\begin{abstract}
The Australian Disability Standards for Education 2005 (Cth) require education providers to make reasonable adjustments in educational assessment so that students with disability can participate on the same basis as other students and be able to demonstrate what they know and can do. Reasonableness is governed by a determination of the balance of interests, benefits and detriment to the parties involved. The Standards require providers to consult with students and associates on adjustments, although guidance on how consultation should occur and how the views of students and associates are to be taken into account is vague. In this article, we identify three principles to be considered in order to put appropriate and effective reasonable adjustments in assessment into practice. While Australian law and assessment contexts are used to examine intentions, expectations and practices in educational assessment for students with disability, we argue that these three principles must be considered in any national education system to ensure equitable assessment practices and achieve equitable educational inclusion for students with disability.
\end{abstract}

Keywords: adjustments; Australia; disability standards; equitable assessment; law; policy; practice; students with disabilities

\section{Introduction}

The Australian Disability Discrimination Act 1992 (Cth) ${ }^{1}$ (DDA, 1992, s. 22) prohibits discrimination in education: in admission for enrolment; in access or limiting access to any benefit provided by an educational authority; or through development of curriculum or training courses with content that could exclude a student from participation, or subject them to any other detriment. The Commonwealth Disability Standards for Education 2005 (DSE, 2005) were formulated and passed under the DDA to bring "clarity and specificity" to these expectations in education (Minister's Foreword). The Standards provide Australian students with disability the right to equal participation in all educational activities (DSE, 2005, Part 3) and on the "same basis" as students without disability (DSE, 2005, $\S \S 4.1,5.1,6.1,7.1$ and 8.2).

The expectations expressed through both the DDA and the Standards are that equitable provision for students with disability will be achieved through "adjustments" made by education providers and authorities to accommodate the needs and learning of students with disability (DDA, 1992, $\S \S 5$ and 6; DSE, 2005, $\S 3.3$ and 3.4; Dickson, 2006, 2007a). Adjustments, "measures or actions" that assist a student with disability

*Corresponding author. Email: j.cumming@griffith.edu.au 
(DSE, 2005, § 3.3) are required in all aspects of educational provision and engagement to enable full participation by students with disability. Education institutions must be proactive in seeking out and eliminating possible causes of detriment for students with disability, instead of reactive after a student complaint of discrimination.

Non-compliance with the Standards is rendered unlawful (DDA, 1992, § 32; Dickson, 2006, 2007a). If non-compliance is established, a student may decide to make a claim of discrimination under the DDA, and is likely to be successful. In Australian law, discrimination may be "direct", less favourable treatment of a person with disability (DDA, 1992, §5) such as failure to enrol a child with disability because of their 10 disability. It may also be indirect, imposition of a condition that is facially neutral but which has an unreasonable discriminatory impact on a person with disability (DDA, $1992, \S 6)$. That is, a person without disability can comply with the condition but a person with disability is not able to comply and the condition has the effect of disadvantaging the person with disability. ${ }^{2}$ An example of a condition with a discriminatory 15 impact is a requirement to read standard written texts in class if a student has serious vision impairment.

The requirement to provide adjustments to meet the needs of students with disability is not open-ended under the Australian Standards. Adjustments must be reasonable, determined by consideration of students' learning needs, the views of the student or their associate, the effect of adjustments on their ability to participate in courses or programmes, the effect on others, costs and benefits of making an adjustment, and the "balance of interests of all parties affected" (DSE, 2005, § 3.4 Note). Benefits for students include both positive learning and social outcomes (Australian Government [AG], 2005, Note 4.5). The views of the student with disability and/or their associate must be sought in advance of the adjustment as to the reasonableness of an adjustment, its effect on equitable inclusion, or whether an alternative "less disruptive and intrusive" adjustment is equally beneficial (DSE, 2005, $\S \S 3.4$ and 3.5). While the Standards compel consideration of student views, the only available case law on point (Walker v. State of Victoria, 2011, p. 284) suggests that from a legal perspective the ultimate decision as to the adjustments that will be made falls to the school:

Once consultation has occurred it is for the school to determine whether any adjustment is necessary in order to ensure that the student is able, in a meaningful way, to participate in the programmes offered by the school. The school is not bound, in making these decisions, by the opinions or wishes of professional advisers or parents. The school is also required to 35 determine whether any reasonable adjustment is possible in order to further the prescribed aims. There may, therefore, be cases in which an adjustment is necessary but no reasonable adjustment is able to be identified which will ensure that the objectives contained in the rele-

AQ2 $\_$vant Disability Standards are achieved. (Walker v. State of Victoria, 2011, p. 284)

It is implicit in the terms of the Standards that an adjustment which is not, on balance, "reasonable" is not required to be made. Even in respect of a "reasonable" adjustment, however, a provider may nevertheless establish that provision of the adjustment would create unjustifiable hardship, determined by consideration of the previous factors, and of any benefit or detriment likely to be suffered by any party. A provider is not required to make such an adjustment (DDA, 1992, §11; DSE, 2005, §§ 453.4 Note and 10.2) and, as suggested above, may decide against such an adjustment. Non-compliance with the Standards would not then be unlawful and any discrimination claim brought by or on behalf of a disappointed student whose 'opinions or wishes' have not prevailed would be unlikely to succeed. ${ }^{3}$ 


\section{The Standards, Adjustments and Educational Assessment}

AQ1 Educational assessment is a major component of education courses and programmes for both teachers and students in every nation. On a daily basis it is used formatively in classrooms to identify students' strengths and weaknesses and to guide future teaching and learning. Families and the community are more aware of assessment undertaken for summative purposes - judgments made about students' achievement in order to report achievement outcomes and students' progress against educational curriculum expectations or an education plan. Further, throughout the world, assessments are increasingly being undertaken for educational accountability purposes, not only to provide data on individual student outcomes but also, when aggregated, on comparative performance of schools, districts, states and national educational outcomes. Equitable assessment for students with disability is, therefore, an important consideration in accountability agendas.

Adjustments in educational assessment for students with disability are specifically noted in the Australian Disability Standards. Measures or action are required to ensure that: assessment requirements of a course or programme are appropriate to students' needs and are accessible; and assessment procedures and methodologies are adapted to enable students to demonstrate the knowledge, skills or competencies being assessed (DSE, 2005, § 6.3). Consultation with the student or student's associate on adjustments to assessment should identify whether an adjustment is necessary to achieve the aim of equitable participation and whether an adjustment can be identified to achieve this aim, with the proviso again that an adjustment must be reasonable, determined by the process described previously (DSE, 2005, § 6.2). Providers may also maintain the "integrity" of courses and programmes through assessment requirements and processes (AG, 2005, Note 4.2; DSE, 2005, $\S 3.4$ Note), especially where assessments lead to conferral of an award and the implicit expectation that holders of the award have "appropriate knowledge, experience and expertise" (DSE, 2005, § 3.4 Note).

A specific component of the Standards is that they empower students with disability. Adjustments are to be made following consultation with the student with disability, and, if necessary, their associate, including family, carers, significant friends, specialists, and persons appointed to speak on their behalf (DSE, 2005, § 1.4 Definitions). The students' interests are identified as "very significant" considerations in identifying appropriate and reasonable adjustments (AG, 2005, Note 4.2). Guidance currently available for schools and staff, and students with disability and their associates, as to how such consultation should occur in practice, and how the views of the students and associates are to be taken into consideration, is limited. Providers are advised that to be compliant with the Standards the consultation process requires: consultation with the student; consideration of whether an adjustment is necessary; if an adjustment is necessary, identification of a reasonable adjustment; and making the reasonable adjustment (AG, 2005, Note 4).

If this process is followed, the provider "cannot be said to have discriminated" (AG, 2005, Note 4). However, the focus in this advice appears to be meeting minimal standards of compliance.

AG advice on the Standards, noting that the Standards do not "explain exactly what 'consult' means", also recommends that providers should "firstly consult and get the ideas of the student themselves" and, if necessary, "talk to important ... family members". The decision in Walker v. State of Victoria suggests that while consultation must occur, the Standards: 
do not, however, require that such consultation take any particular form or occur at any particular time. Those involved may meet formally or informally. Discussions can be instigated by either the school or the parents. Consultation may occur in face-to-face meetings, in the course of telephone conversations or in exchanges of correspondence. (Walker $v$.

$\mathrm{AQ3}_{\text {ג }}$ State of Victoria, 2011, p. 284)

Consultation between providers and students should try, it is suggested, to cover at least four points from the perspectives of the relevant parties:

- Work out what the challenges, needs or barriers are for the student. The student should provide medical and therapist reports that help to explain their disability and what adjustments are needed.

- Suggest ways to overcome these things. In other words, what adjustments could the education provider make to overcome these things?

- Discuss whether you think these adjustments are reasonable. Is there another easier and better way to overcome these things? In other words, is there a different adjustment that you didn't think of earlier?

- Ask the education provider to provide you with a letter about what was discussed when you were consulting and what decisions were made. Ask the education provider to give you a specific date when they will notify you about what adjustments will or will not be made. (Department of Education, Employment and Workplace Relations, 2008)

Independent experts may be involved to provide professional reports (AG, 2005, Note 4.2). Consultation should continue over the duration of a student's enrolment and occur regularly. Processes should also be "accessible and transparent" (AG, 2005, Note 4.2).

\section{Issues for Implementation of Reasonable Adjustments to Assessment}

A core issue in Australian provision of reasonable adjustments in assessment for students with disability, seeking the views of student and associates, and considering factors such as whether "there [is] another easier and better way to overcome" barriers, is that students and families are not in informed positions of power. They have limited knowledge of assessment approaches and of the types of adjustments and alternative approaches they could expect to occur. Most often, parents and others will rely on their own very limited experiences of traditional school assessment.

Not only students and parents may have limited information on assessment adjustments and alternatives; limited teacher knowledge of quality assessment practices in regular classroom activities has often been cited in the research literature (Brookhart, 2004; Cox, 2011; Stiggins \& Conklin, 1992), with considerable professional development undertaken to inform and improve regular teacher classroom assessment practices (Black \& Wiliam, 1998; Chappuis, Stiggins, Chappuis, \& Arter, 2012). The expected capability of teachers to meet diverse learning needs and alternative assessment approaches in Australian curriculum, and the additional requirements of the Australian Disability Standards, exacerbate this problem (Australian Curriculum Assessment and Reporting Authority [ACARA], 2011b). Professionals such as therapists and 45 psychologists may have specialist diagnostic skills but are also not necessarily in a position to inform discussions on alternative educational assessment approaches. 
The AG has committed considerable funding to initiatives to improve the quality of teaching practice in general, with funding specifically committed to assist teachers and schools to support students with disability and improve their learning outcomes, including identification of "strategies which most improve the learning experiences of students with disability" (AG, 2011a, p. 19). Funding of AUS\$200 million over two-and-ahalfyears incorporates professional development for teachers in many areas, including how to adapt curriculum and assessment to the needs of students with disability.

A second core issue in the provision of reasonable adjustments in assessment in Australia for students with disability is that the current approach of idiosyncratic, and private, consultation means that systematic evidence on how effective assessment adjustments have been undertaken, providing guidance for policy-makers, school principals and teachers, students and families, is not available. An ongoing and critical concern that parents and students with disability have identified in the practice of inclusive education is the ad hoc nature in which it is implemented from school to school and from classroom to classroom. Echoing the previously cited government advice on adjustment processes, families and students want transparent and informed processes through which schools can review their inclusive practices and provide a standard response to the inclusion of students, rather than the quality of inclusive practice "relying on chance" (Queensland Parents for People with Disability Inc [QPPD], 2011, p. 33). More consistent and standard inclusive education practices require more public and careful consideration of the processes of adjustment in all aspects of educational provision from enrolment to courses and programmes. They also need more informed input on the types of assessment adjustments that can occur.

In the following discussion in this article we explore three principles that can inform the development of appropriate and effective adjustments to educational assessment for students with disability. Given the universality of many assessment practices, and of commitment to inclusive education for students with disability, we consider how these principles apply in any educational system seeking to provide inclusive and equitable

AQ4 $_{\curlywedge}$ education for students with disability.

First, however, we consider the importance of stringent, not token or compliant, efforts to give the fullest commitment to provision of appropriate and effective adjustments in educational assessment for students with disability.

\section{The Need for Serious Intent in Making Reasonable Adjustments in Assessment for Students with Disability}

Enacting quality but "reasonable" adjustments in assessment occurs at the interface of three theoretical and practice frameworks: legal compliance requirements and case law in discrimination in educational assessment; best education practice for students with disability; and effective educational assessment practice. We consider that when legislation, policy and research in these three areas are considered, it is clear that implementation of high-quality adjustments in assessment are necessary. It is possible, within a legal framework, for schools and teachers to meet legal compliance through minimal effort-for example, the provision of extra time or provision of separate space in test situations, excusing a student from participation in inappropriate assessment if the perceived alternative approach requires considerable expenditure, assessing a lower

curriculum expectation rather than altering assessments for fear of loss of reliability. However, while these adjustments might meet the letter of the law as special arrangements for students with disability, when findings from educational research in the areas 
of quality assessment and quality education of students with disability are integrated with legislative and policy intentions, it becomes apparent that serious endeavours to provide the highest quality assessment approaches are necessary to ensure equitable educational outcomes of students with disability.

First, all three areas-law and policy, best education practice for students with disability, and effective educational assessment - have current and predominant themes that put the individual - in this case, the student with disability - central to social expectations of equity, effective educational provision, and educational assessment.

We have discussed the expectations in law, and issues in consultation with students with disability and associates to determine appropriate educational assessment adjustments. However, the empowerment of students with disability by the Standards echoes broader approaches of social justice and valuing all individuals. The DDA and Standards are broadly framed Australian legislation committed to people with disabilities having the "same rights to equality before the law as the rest of the community" (DDA, 1992, § 5). The AG Social Inclusion Agenda states a vision of Australia as a socially inclusive society in which all Australians are valued. Full participation by individuals with disability in education and training, work, and the community are national goals. The Melbourne Declaration of national education goals for young Australians positions education as central to a "democratic, equitable and just society" and ensuring Australia's "economic prosperity and social cohesion" (Ministerial Committee for Employment, Education, Training and Youth Affairs, 2008, pp. 4-5 and 10). The Declaration emphasises the expectation that all students, including students with disability, have the right to equity and excellence in education and to become "successful learners, confident and creative individuals, and active and informed citizens" (2008, p. 7).

Improving the participation gap between employment of only $50 \%$ of individuals 30 with mild and moderate disabilities, compared with $80 \%$ of those without disabilities, is one of six priority areas for action in Australian policy (Australian Social Inclusion Board Indicators Working Group, 2009). Educational attainment, and specifically Year 12 completion, has been identified as a key factor affecting further study and employment. At present, only $62 \%$ of students with disability complete Year 12 compared with $78 \%$ of students without a disability (Australian Bureau of Statistics, 2011); improving Year 12 completion is a national goal. It is arguable that appropriate educational assessment can be a key factor in student success and retention to Year 12.

Goals of the DDA, Standards and Melbourne Declaration are therefore not just to ensure inclusive practices and equity in the immediate conduct of schooling, but, long term, to ensure full participation in post-school life and employment opportunities, and to enhance society overall. Similar social and educational expectations can be found in many countries.

Most importantly, as identified in the Australian Standards, students with disability should have a voice to influence decisions that affect them (AG, 2011b). This reflects the general expectations of the United Nations Convention on the Rights of Persons with Disabilities that "persons with disabilities should have the opportunity to be actively involved in decision-making processes about policies and programmes, including those directly concerning them" (United Nations, 2007, Preamble), and of the Convention on the Rights of the Child that a child capable of forming their own views has "the right to express those views freely in all matters affecting the child, the views of the child being given due weight in accordance with the age and maturity of the child" (United Nations General Assembly, 1989, Article 12). 
The commitment by the Standards to providing students with disability with a voice in adjustments to educational assessment and provision does not just reflect legislation and policy expectations for a more socially just society. It also reflects research on best educational provision, for all students, including students with disability. Self-determination, including the ability to self-actualise, set goals, make decisions and evaluate one's personal outcomes and successes (Lee, Wehmeyer, Palmer, Soukup, \& Little, 2008; Mason, McGahee-Kovac, Johnson, \& Stillerman, 2002), is identified as best educational practice for students with disability. Self-determination of educational pathways is linked to both enhanced academic success and improved post-school outcomes (see, for example, Field, Sarver, \& Shaw, 2003). Student participation in the development of their own individual education plans has been stressed by researchers who have found that secondary students who participate in their own educational goal setting and planning are more likely to achieve their goals, improve their academic skills, and gain better employment and quality of life as adults (Carter, Lane, Pierson, \& Glaeser, 2006; Martin et al., 2003). Promoting students' self-determination is regarded as best practice in education of transition-age youth with disability (Carter et al., 2006). The role the Standards give students with disability in the significant educational area of assessment is clearly important to their educational progress.

The essential need for students with disability to have a voice in appropriate assessment adjustments has also been emphasised in educational assessment. Roach and Beddow (2011) consider most students with and without disability fully capable of expressing opinions about assessment. Roach and Beddow see integration of student voice as essential in "development and validation of inclusive and accessible assessment strategies", expanding epistemological and methodological frameworks that dominate measurement and enhancing both assessment quality and interpretation of outcomes in context (2011, p. 254). Summarising research on assessment using the student voice, they found that tests modified through student consultation improve student motivation and sense of efficacy, aspirations to complete high school and post-secondary education. Overall, the educational assessment research community highlights the importance of students engaging with assessment goal-setting and self-assessment of their own learning progress for successful student learning (Broadfoot \& Black, 2004). Research has demonstrated that through appropriate adaptation of instrumentation for students with a range of disability, all students are able to participate in providing opinions on educational matters of value to them (Webster and Carter, 2010a).

From this congruence of law, policy, effective provision for students with disability, and assessment research, it is clear that compliance in the provision of reasonable adjustments in assessments for students with disability is not to be undertaken just to meet minimum legal requirements. High-quality adjustments are essential for the future well-being of inclusive and equitable societies and for educational outcomes for students with disability.

\section{Developing Effective Reasonable Adjustments to Assessment in Practice}

The Australian Standards for reasonable adjustments to assessments expect that:

- adjustments should make assessment appropriate to the student and accessible;

- assessment should allow a student to demonstrate their knowledge; and

- the views of the student and families must be sought prior to an adjustment. 
Enacting these effectively is not simple. We identify three core principles that underpin appropriate and effective adjustments to assessment for students with disability in a range of educational contexts. The first principle is that equity and fairness in assessment do not mean that the same assessment must be undertaken by all students or that an adjustment is just tinkering with the assessment undertaken by other students. The second principle is that the requirement for reasonable adjustments is not just to provide minor adjustments: adjustments must maximise opportunity for students with disability to demonstrate their knowledge, and should be against appropriate standards for the students. The third principle is that it is important not to patronise students with disability by assuming that non-participation in or exemption from assessments is their best option.

\section{Principle 1: Ensuring an equitable approach to assessments and adjustments}

Key to this principle is an understanding that equity in assessment does not require the same assessment to be undertaken by all students. Nor does equity in assessment require only minor adjustment with the assessment form that other students may be completing. These do not define fairness and such an approach embeds cultural capital,

20 in all its forms, as the prime predictor of academic success (Cumming, 2012; Stobart, AQ6 2008).

Adjustments in daily classroom assessment activities are at the discretion of schools. In Australia, and elsewhere, classroom teachers are expected to tailor provision to suit individual student needs (ACARA, 2011b; Cumming, 2012). Australia's new national

25 curriculum retains principles of design from previous state syllabuses, providing frameworks of knowledge and skills with flexibility for adaptation by schools and teachers to suit their community. Further, within this structured environment, education provision is to be tailored to suit "the current levels of learning of individual students and the different rates at which students develop" (ACARA, 2011b, p. 10) and a "diverse range of

30 learning and assessment needs" (2011b, p. 17). This matches the expectation of parents and students with disability that inclusion is practised through differentiated instruction and curriculum modification within a classroom, rather than use of teaching assistants (QPPD, 2011). Similar expectations for the education of students with disability exist in England and the United States (Cumming, 2012).

35 It is important, then, as the starting point to an adjustment, for teachers to go back to basic purposes underpinning the act of assessment. Whatever the use that will be made of student assessment outcomes, the primary purpose of an assessment at any time is to determine what a student knows, and can do, against some standard such as curriculum expectations or a student's individual education programme. 40 The preliminary stage of identifying an adjustment to an assessment is therefore to determine what explicit knowledge or skill is being assessed. Often in assessment, the secondary form of assessment gets in the way of the primary purpose (Cumming \& Maxwell, 1999). Multiple choice mathematics items that involve considerable literacy skill but are intended to assess only simple arithmetic knowledge are classic 45 examples.

It is important also to identify the nature of the knowledge or skill that is being assessed: it may be content knowledge; it may be process or strategic knowledge; it may be a physical skill. When these basic aspects of what is to be assessed have been determined, then it is appropriate to consider how many different ways there are to assess the knowledge or skill and which way is most suitable for a specific student. 
Teachers should focus on the individual student and knowledge to be assessed, not other students.

Teachers can feel anxious that they have no benchmark to ensure they are validly and reliably assessing an individual student's knowledge at a particular level. However, this can be achieved by discussion of the assessment approach and the student's demonstration of knowledge with other teachers. This approach, known as social moderation (Maxwell, 2010), underpins the system of school-based externally-moderated teacher judgment of student performance for school-leaving certification in Queensland. In this system, high-stakes assessment outcomes are quality assured against state-wide achievement standards through evidence of student achievement and of the knowledge and skills that have been assessed, even though not all students have completed the same assessment tasks (Maxwell \& Cumming, 2011). The same approach has been implemented for alternative assessments for students with disability under No Child Left Behind accountability assessment requirements in the United States (Kleinert, Browder, \& Towles-Reeves, 2009).

The Australian Standards allow providers to maintain the integrity of content and standards in assessment where this is important. This encompasses assessments in vocational areas assessed against statements of competency for certification and in subjects and courses at an important educational juncture such as high school graduation or certification of a professional qualification. Following the previous discussion, however, the critical issue is what is being assessed, followed by what restrictions on assessment approach are explicitly, not implicitly, in place.

As an example, the Australian curriculum has identified expected levels of achievement for each curriculum area. A sample statement for mathematics for Year 4 is:

[By the end of Year 4 students] recall multiplication facts up to $10 \times 10$ and the related division facts. (ACARA, 2012, pp. 30 and 34)

This statement of the standard does not say how students must be able to recall multiplication facts. The assessment task and response could be posed orally or by signing, writing, or pointing.

In general, compared with primary school teachers, secondary school teachers have been found less likely to be flexible in adapting curriculum content and assessment for inclusion of students with disability (Shaddock, Giorcelli, \& Smith, 2007). The issue of explicit versus implicit understandings of assessment expectations has been explored in an Australian court prior to the Disability Standards. A student who, due to physical and sensory impairments, could not physically read or write in examination conditions brought a discrimination claim against his state school because he was being denied the opportunity by the school to study English and German, in the belief he would not be able to complete assessments (Beanland $v$. State of Queensland \& Anor, 2008). Discussion at the Tribunal hearing included the meaning of "reading and writing", oral language, and syllabus requirements that "students need to show that they can understand written and visual text" (2008, p. 33). The student was unsuccessful in his claim because he had left the government school before it was able to resolve the issue and identify mandatory and flexible components of assessment. However, he had by then enrolled in a private school that identified ways to accommodate his needs within the same quality assurance and certification system. 
Principle 2: Setting appropriate expectations and adjustments to enable students with disability to demonstrate their knowledge

This principle has two components: assessment against appropriate and accessible curriculum for the student, and reasonable adjustments that allow students to demonstrate their knowledge to an optimal level.

\section{Component 1: Assessment against appropriate and accessible curriculum for the student with disability}

The Standards indicate that students should be assessed against curriculum "appropriate to the needs of the student and accessible to them", implying appropriate curriculum content and expectations. This should not be automatically assumed to mean that students with disability will be working at a lower standard level than other students in a classroom.

In the earlier example of the Year 4 multiplication standard of achievement, the content expectation may need to be modified. Is "recall" the essential learning here, rather than understanding, if a student has memory difficulties? Research has long shown that students with intellectual disabilities can develop mathematical understanding and effective solution strategies while unable to develop long-term memory of such facts (Baroody \& Snyder, 1983; Cumming \& Elkins, 1999; Finnane, 2007). An appropriate adjustment to these expectations for a student with an intellectual disability could be that the student is able to do a multiplication of digits up to $10 \times 10$ with assistance (e.g., using a calculator or other electronic device). The student is able to work with content at the same level but in a different way. The default is not necessarily the Year 3 standard-addition facts and recall of more simple multiplication facts (ACARA, 2012) - if recall is not likely to ever be achieved. The goal of teaching and assessing diversity under curriculum in Australia is not to say a student with disability is only at Year 3 level if they cannot achieve some aspects of Year 4 expectations, but to provide evidence of the combination of knowledge and skills the student with disability has across a range of Year levels. Addressing diversity may mean that a student with disability may not be able to achieve some aspects of a curriculum; this should not negate identification of what other aspects they can achieve.

Disability in the DDA, and hence Standards, is defined broadly to encompass past, existing and future disabilities relating to: mental functions; disease or illness; body malfunction or malformation; and emotional disorders (DDA, 1992, § 4). It includes disorders affecting learning and emotions and behaviour. Eight to $10 \%$ of students are estimated to have a disability (Australian Bureau of Statistics, 2010; Prasser, 2009) with numbers increasing as definitions broaden. A recent project (PriceWaterhouseCooper, 2011) found the most prevalent reported disabilities were learning (30\%), intellectual $(16 \%)$, autistic spectrum (14\%), mental, social or emotional disorder $(12 \%)$ and severe behaviour disorders $(9 \%)$. Severe physical disorders were low incidence, ranging from $2 \%$ to $5 \%$. Many of the more prevalent disabilities are associated with high-level cognitive functioning but may have import for a student's capacity to sit still for prolonged times, to concentrate on assessments, to participate in groups, or to make presentations in public. Again, the degree to which format is critical to the assessment needs to be 45 considered. In one Australian case, for example, participation in a group for assessment was found to be essential to the learning being assessed. In this vocational education case, Reyes-Gonzalez v. NSW TAFE Commission (2003), a student with schizophrenia 
that impacted on his capacity to participate in the standard learning schedule made a

AQ7 claim of discrimination against his TAFE college for failure to treat him on the same basis as others without his impairment on a number of grounds. While the college made considerable accommodations for him, staff presented evidence that areas where the student had difficulty, such as participating and presenting in groups, were fundamental requirements to course outcomes.

The primary approach in provision in education is to "characterise" and label a student with disability in terms of categories. However, students with disability may have a range of needs. Further, students with disability may be able to achieve at a very high level in some or all areas; they are not necessarily low achievers - consider internationally renowned physicist Stephen Hawking. This issue has emerged as a difficult one for schools in Australia who have difficulty coping with students with disability who are also very abled in some areas. An example of this emerged in the case of Rhys Chinchen (Chinchen v. NSW Department of Education and Training, 2006), a child who was initially placed in an extension class because of his "exceptional ability". However, the school considered that he lacked "motivation towards his schoolwork" because he did not keep pace with the class, and he was reassigned to a mainstream class. Rhys had a specific disability that affected his planning and fine motor skills (motor dyspraxia), and it was for this reason that he did not manage to keep up with the expectations of his extension class and assessments. Some claims of discrimination and detriment were found in a claim under New South Wales discrimination law, although the matter was finally settled out of court and appeals on the decision were not heard. The issue for adjustments in regular classroom assessments is therefore whether teachers are not only modifying curriculum expectations to meet students with diverse learning needs but also using a wide range of assessment approaches to gauge learning outcomes and progress for students with disability.

\section{Component 2: Reasonable adjustments to allow students to demonstrate their knowledge to an optimal level}

The second component of this principle is that reasonable adjustments to assessment are required to enable the student with disability to demonstrate their knowledge, skills and competencies, implicitly to a high level. Good assessment strives to identify as validly and reliably as possible what students know and can do (Pellegrino, Chudowsky, \& Glaser, 2001). It is common in standardised approaches to assessment to provide students with disability with a range of adjustments, such as a reader or amenuensis, and extra time. Usually, extra time requirements are strictly monitored, perhaps allowing an additional 10-20 minutes maximum per hour of formal examination.

However, surprisingly little research exists on the adequacies of assessment adjustments for students with disability to allow students to demonstrate their skills to a highest level. Consider the adjustment of extra time in an examination. Overall, research that has been undertaken shows that very liberal time extensions should be provided (Nester, 1993; Ragosta \& Wendler, 1992; Sireci, Scarpati, \& Li, 2005; Zuriff, 2000). This takes us back to the fundamental purpose of determining what learning is being assessed and what is the appropriate approach. As Elliott and Marquart noted:

Time and speed of response are constructs that rarely, if ever appear in the state or district content standards that large-scale tests are designed to measure. Time is actually more of a test management issue than a construct to be measured in learners. (2004, pp. 349-350) 
The issue is sufficiency or optimality of adjustments. Prior to the Standards, it was accepted that adjustments were sufficient if a student with disability achieved a passing grade, to ensure no advantage was given to the student with disability. In Hinchliffe $v$. University of Sydney (2004, p. 105), a university argued against a discrimination claim by a high-achieving student with disability that course materials were inadequately prepared by stating that "a pass grade" was the only condition imposed for graduation.

10 While the tribunal was not impressed by this argument, the case was lost by the complainant on another point. However, in another case, a student with disability (attentiondeficit hyperactivity disorder) was denied additional time in a New South Wales Higher School Certificate examination in English that he had argued would allow him to demonstrate a higher standard of achievement (BI v. Board of Studies, 2000, p. 34). The court accepted that, in compliance with state policy at that time, completion of a required practice test showed he could achieve an "average" standard under the set time frame. The state argued that more time might advantage the student. By contrast, in a discrimination challenge regarding educational provision, a student was successful in obtaining optimal provision in terms of her choice of sign language in the classroom to

20 allow her to reach her "full educational potential" (Dickson, 2005/06; Hurst v. State of Queensland, 2006). Again, the defence argument was that the Australian discrimination act did not require the student to be "given an optimal education" but only a "satisfacAQ8 tory" education (Hurst v. State of Queensland, 2006, p.99). The final appeal turned on the interpretation of the student's ability to comply versus cope. Noting that this student had demonstrated above-average achievement in favourable learning circumstances, the court found that the student would be seriously disadvantaged if the most appropriate educational assistance and preferred choice of sign language interpretation was not given.

A question is how, post Hurst $v$ State of Queensland, the facts in BI v. Board of 30 Studies might be treated in a challenge to compliance with the Australian Disability Standards. If the Standards are to be interpreted as requiring optimal adjustments to allow students with disability to demonstrate their knowledge, then adjustments must be planned to ensure the range of performance a student can exhibit is not artificially constrained by characteristics of the assessment form or factors such as time. If equity for all students is a concern, and, as research shows, all students will benefit from extra time (Sireci et al., 2005), the issue may be that the role of time constraints in an assessment and as a predictor of assessment outcomes needs to be examined.

\section{Principle 3: Equity in assessment participation should be considered through the eyes of the student}

40 The Standards require that students should be consulted about appropriate assessment adjustments. Research is showing that such consultation may surprise teachers, who see much of the role as protecting students with disability from failure. While failure in an assessment might be demoralising for a student with disability, this is the case for any student. Students with disability have the right not only to succeed and demonstrate 45 their knowledge but also, like other students, to fail. Recent research has demonstrated that appreciating failure is an important component of learning (Autin \& Croizet, 2012). However, students with disability should not fail because an assessment is not accessible nor because targets are consistently unrealistic. Students with disability also express the same need to belong as all students do (QPPD, 2011). Conversely, other students 50 perceive students with disability more equally when all students do the same things and 
teachers model equitable treatment, and not special treatment, for students with AQ9 ${ }_{\wedge}$ disability (Webster \& Carter, 2010b). Assessment is just one aspect of education where this can also apply.

The social impacts of assessments and reasonable adjustments to assessment may be as important for students with disability as the valid reporting of learning achievement. As noted, the Standards identify positive outcomes from assessment to include affective outcomes (AG, 2005, Note 4.4). In a recent study of secondary students with vision impairment in the final year of schooling in Queensland, Whitburn (2011) found that several students reported high levels of frustration after they had been unilaterally exempted from participation in a standardised test based on their status as part of the special education programme, and without any consultation with the students or their parents. Participation in the test was required for students seeking a ranking for university entrance, and optional for other students. These students expressed concern that being excluded from this test could impact their ability to enter tertiary studies but also expressed their disappointment in being excluded from part of their schooling, which they considered a rite of passage. One student, in particular, stated that he would take the test anyway, and would fight them because they were "discriminative people".

Students with disability have demonstrated acute awareness of the sense to which they belong and are able to participate in educational activities and opportunities available to students without disability. Structures and boundaries set by systems, schools and teachers (Davis \& Watson, 2001) and assumptions made about limited or restricted capacities of students with disability, without consultation with students (McMaugh, 2011), contribute to ongoing discrimination in practice. While research on the perceptions of students with disability on assessment appears to be very limited, apart from the work of Roach and Beddow (2011), a starting point for developing reasonable adjustments in consultation with students may be to assume participation rather than protection and possible discriminatory patronising of students.

An area of ironic protection in Australia occurs through the major accountability assessments known as the National Assessment Program-Literacy and Numeracy (NAPLAN). NAPLAN has evolved from an early accountability system that sought to identify students at risk and in need of early intervention (Department of Education, Science \& Training, 1998), including students with disability. The expectation is that nearly all students will: reach minimum identified standards in literacy and numeracy (with the exception of a very small percentage of students), and will be able to participate in the NAPLAN tests. Available adjustments to the standardised test forms are very limited. The approach of the testing authority is that more flexible adjustments or assessments may create an unfair advantage for a student with disability, compromising the "integrity" of the test form. Adjustments are to neither advantage nor disadvantage students with disability (ACARA, 2011a).

As a result, it is acknowledged that not all students with disability will be able to access and participate in NAPLAN testing. These students are exempted. Under current accountability reporting arrangements, such students are deemed not to meet minimum standards, but with no diagnostic assessment information provided on their strengths and weaknesses. Further, students with disability who are exempted from NAPLAN testing are included in the population data reported for school performance records ${ }^{4}$ as below standard. The question arises as to the benefit to either the school or the student of non-participation in the test. Having a go at the test with some assistance in recording responses may not be to any greater disadvantage for students with disability than 
exemption and may at least make the students feel part of an activity that has also become an important Australian school ritual.

\section{Conclusion}

The purpose of this article has been to draw attention to issues in providing appropriate assessments to assess the knowledge and skills of students with disability. The discussion is framed by the Australian legal context, the requirement both for adjustments to be made in educational provision for students with disability to meet their needs and for consultation with students and associates to inform such adjustments. We have discussed the social imperatives that underpin societies striving to value diversity, to empower all individuals, and to build strong and prosperous societies where all are able to contribute, to the maximum extent possible, to their own well-being and the well-being of others. We have discussed the importance of endeavouring to go beyond mere legal compliance to provide appropriate education for students with disability.

The focus of the discussion has been assessment in schools of students with disability. The Australian Disability Standards require reasonable adjustments to assessment 20 for students with disability. We identify three principles that need to be addressed to enact the legislative intent for effective and quality adjustments to educational assessment. At a time when solutions for provision to support the needs of students with disability turn increasingly to technology and expensive approaches, the three principles we propose are all within expectations of quality teacher knowledge and practice. They are extensions of current expectations for all students. A provider could not argue unjustifiable hardship for being required to think about what a student is learning and how they are to be assessed.

Through analysing Australian legislation and practice, in conjunction with international research on assessment and students with impairment, we present three core prin30 ciples that need enactment in any national education system to ensure equitable assessment for students with impairment. The principles require a return to revisiting the primary purpose of assessment, a consideration of the appropriate curriculum expectations for assessment, and the need to enable students with disability to demonstrate their strengths and weaknesses. As a final principle, we suggest that ensuring students with disability "have a fair go" might be the most core principle of all.

As a young American 11-year-old student who is blind, Jack McPadden, interviewed during a dance exhibition (he also holds a junior black belt in a martial art), recently said:

... I can do basically anything that a sighted person can do, as long as it is modified for me, I could even fly a plane-someone just needs to direct me. Something that should not even be asked is, can he? Of course he can. Absolutely. (Kahn, 2011, p. 31)

And when he cannot, he will know he has tried. Most of all, we do need to ensure the students decide and advise.

\section{Funding}

45 There was no research funding for this study, and no restrictions have been imposed on free access to, or publication of, the research data. 


\section{Notes}

1. Federal legislation in Australia is referred to as Commonwealth (Cth).

2. For a comprehensive overview of the operation of Australian anti-discrimination law in the context of education, see Dickson (2007b).

3. However, if a school reaches an ill-informed decision on what is or is not reasonable, it is vulnerable to legal action. See, for example, the discussion of Hurst (2006). While this is a pre-Standards case, it illustrates the proposition that a school which ignores a student's legitimate concerns about the way his or her education is delivered and rejects sensible suggestions as to reasonable adjustment to that delivery may be successfully sued.

4. Published online: www.myschool.edu.au.

\section{References}

Australian Bureau of Statistics (ABS). (2010). Disability, ageing and carers. Australia 2009. Canberra, ACT: Author.

Australian Bureau of Statistics (ABS). (2011). Australian social trends. March 2011. Year 12 attainment. Canberra, ACT: Author.

Australian Curriculum Assessment and Reporting Authority (ACARA). (2011a). National Assessment Program Literacy and Numeracy handbook for principals. Brisbane, QLD: Queensland Studies Authority.

Australian Curriculum Assessment and Reporting Authority (ACARA). (2011b). The shape of the Australian curriculum 3.0. Retrieved from http://www.acara.edu.au

Australian Curriculum Assessment and Reporting Authority (ACARA). (2012). The Australian curriculum. Mathematics. V. 3.0 Retrieved from http://www.australiancurriculum.edu.au/ Mathematics/Rationale

Australian Government (AG). (2005). Disability Standards for Education 2005 Guidance Notes. Canberra, ACT: Author.

Australian Government (AG). (2011a). Foundations for a stronger, fairer Australia. Canberra, ACT: Department of Prime Minister and Cabinet.

Australian Government (AG). (2011b). Social inclusion. Retrieved from socialinclusion.gov.au.

Australian Social Inclusion Board Indicators Working Group (ASIBIWG). (2009). A compendium of social inclusion indicators. How's Australia faring? Canberra, ACT: Australian Government.

Autin, F., \& Croizet, J.-C. (2012, March 5). Improving working memory efficiency by reframing metacognitive interpretation of task difficulty. Journal of Experimental Psychology: General. Advance online publication. doi:10.1037/a0027478

Baroody, A. J., \& Snyder, P. M. (1983). A cognitive analysis of basic arithmetic abilities of TMR children. Education and Training of the Mentally Retarded, 18, 253-259.

Beanland v. State of Queensland \& Anor (2008) QADT 5.

BI v. Board of Studies. (2000) NSWSC 921.

Black, P., \& Wiliam, D. (1998). Inside the black box: Raising standards through classroom assessment. London: NfERNelson.

Broadfoot, P., \& Black, P. (2004). Redefining assessment? The first ten years of assessment in education Assessment in Education: Principles, Policy and Practice, 11, 7-27.

Brookhart, S. M. (2004). Grading. Upper Saddle River, NJ: Prentice-Hall.

Carter, E. W., Lane, K. L., Pierson, M. R., \& Glaeser, B. (2006). Self-determination skills and opportunities of transition-age youth with emotional disturbance. Exceptional Children, 72, 333-346.

Chappuis, J., Stiggins, R., Chappuis, S., \& Arter, J. (2012). Classroom assessment for student learning: Doing it right - using it well (2nd ed). Upper Saddle River, NJ: Pearson.

Chinchen v. NSW Department of Education and Training [2006] NSWADT 180.

Cox, K. B. (2011). Putting classroom grading on the table: A reform in progress. American Secondary Education, 40, 67-87.

Cumming, J. J. (2012). Valuing students with impairment. Dordrecht, The Netherlands: Springer.

Cumming, J. J., \& Elkins, J. (1999). Lack of automaticity in the basic addition facts as a characteristic of arithmetic learning problems and instructional needs. Mathematical Cognition, 5, $149-180$ 
Cumming, J. J., \& Maxwell, G. S. (1999). Contextualising authentic assessment. Assessment in Education: Principles, Policy and Practice, 6, 177-194.

Davis, J. M., \& Watson, N. (2001). Where are the children's experiences? Analysing social and cultural exclusion in "special" and "mainstream" schools Disability \& Society, 16, 671-687.

Department of Education, Employment and Workplace Relations (DEEWR). (2008). Disability Discrimination Act Education Standards. Retrieved from www.ddaedustandards.info/obligations.php

Department of Education, Science \& Training (DEST). (1998). National literacy and numeracy plan. Retrieved from http://curriculum.edu.au/mceetya/stepping/projects/16/rec16-commonwealth.htm

Dickson, E. A. (2005/06). Coping, complying and indirect discrimination: Hurst v. State of Queensland. Australia and New Zealand, Journal of Law and Education, 10/11, 103-108.

Dickson, E. A. (2006). Disability Standards for education and the requirement of reasonable adjustment. Australia and New Zealand Journal of Law and Education, 11, 23-42.

Dickson, E. A. (2007a). Disability Standards for education and reasonable adjustment in the tertiary education sector. Australia and New Zealand Journal of Law and Education, 12, 25-41.

Dickson, E. (2007b). Equality of opportunity for all? An analysis of the effectiveness of the Anti-Discrimination Act 1991 (Qld) as a tool for the delivery of equality of opportunity in education to people with disabilities (Unpublished $\mathrm{PhD}$ thesis). University of Queensland, Brisbane, Australia.

AQ10 Disability Discrimination Act 1992 (Cth) (DDA). (1992).

AQ11 Disability Standards for Education 2005 (Cth) (DSE). (2005).

Elliott, S. N., \& Marquart, A. M. (2004). Extended time as a testing accommodation: Its effects and perceived consequences. Exceptional Children, 70, 349-367.

Field, S., Sarver, M. D., \& Shaw, S. F. (2003). Self-determination. A key to success in postsecondary education for students with learning disabilities. Remedial and Special Education, 24, 339-349.

Finnane, M. (2007). The role of fluency in mathematical development: Factors associated with early learning difficulties in mathematics. Unpublished $\mathrm{PhD}$ Thesis. University of Queensland, Brisbane, Australia.

Hinchliffe v. University of Sydney. (2004). FMCA 85.

Hurst v. State of Queensland. (2006). FCAFC 100.

Kahn, J. P. (2011, May 19). Dancing with feeling. The Boston Globe, Boston, p. 31.

35 Kleinert, H., Browder, D., \& Towles-Reeves, E. (2009). Models of cognition for students with significant cognitive disabilities: Implications for assessment. Review of Educational Research, 79, 301-326.

Lee, S. H., Wehmeyer, M. L., Palmer, S. B., Soukup, J. H., \& Little, T. D. (2008). Self-determination and access to the general education curriculum. The Journal of Special Education, 42, 91-107.

Martin, J. E., Mithaug, D. E., Cox, P., Peterson, L. Y., van Dycke, J. L., \& Cash, M. E. (2003). Increasing self-determination: Teaching students to plan, work, evaluate, and adjust. Exceptional Children, 69, 431-447.

Mason, C. Y., McGahee-Kovac, M., Johnson, L., \& Stillerman, S. (2002). Implementing studentled IEPs: Student participation and student and teacher reactions. Career Development for Exceptional Individuals, 25, 171-192.

Maxwell, G. S., \& Cumming, J. J. (2011). Managing without public examinations: Successful and sustained curriculum and assessment reform in Queensland. In L. Yates, C. Collins, \& K. O'Connor (Eds.), Australia's curriculum dilemmas: State perspectives and changing times (pp. 202-222). Melbourne, VIC: Melbourne University Press.

Maxwell, G. S. (2010). Moderation of student work by teachers. In B. McGaw, P Peterson, \& E. Baker (Eds.), International Encyclopedia of Education (Vol. 3, pp. 457-463). Oxford: Elsevier.

McMaugh, A. (2011). En/countering disablement in school life in Australia: Children talk about peer relations and living with illness and disability. Disability \& Society, 26, 853-866.

55 Ministerial Committee for Employment, Education, Training and Youth Affairs (MCEETYA). (2008). Melbourne declaration on education goals for young Australians. Retrieved from www.mceecdya.edu.au

Nester, M. A. (1993). Psychometric testing and reasonable accommodation for persons with disabilities. Rehabilitation Psychology, 38, 75-85. 
Pellegrino, J. W., Chudowsky, N., \& Glaser, R. (Eds.). (2001). Knowing what students know. Washington, DC: The National Academies Press.

Prasser, S. (2009). Students with disabilities in Queensland Independent schools. Equality for all. Choice \& Diversity. Brisbane: Association of Independent Schools of Queensland Inc.

PriceWaterhouseCooper (PWC). (2011). Trial of a model for collecting nationally consistent data on school students with disability. Sydney, NSW: Author.

Queensland Parents for People with Disability Inc. (QPPD). (2011). Diving for pearls. An account of parents" quest for an inclusive education in Queensland. Brisbane, QLD: Author.

Ragosta, M., \& Wendler, C. (1992). Eligibility issues and comparable time limits for disabled and nondisabled SAT examinees. N.Y.: CEEB Report No. 92-5.

Reyes-Gonzalez v. NSW TAFE Commission [2003] NSWADT 22 (Unreported, Ireland J, Members Silva and Strickland, 3 February 2003) (Reyes-Gonzalez).

Roach, A. T., \& Beddow, P. A. (2011). Including student voices in the design of more inclusive assessments. In S. N. Elliott, R. J. Kettler, P. A. Beddow, \& A. Kurtz (Eds.), Handbook of accessible achievement tests for all students (pp. 243-254). Dordrecht, The Netherlands: Springer.

Shaddock, A., Giorcelli, L., \& Smith, S. (2007). Students with disabilities in mainstream classrooms. A resource for teachers. Canberra, ACT: Australian Government Department of Education, Employment and Workplace Relations.

Sireci, S. G., Scarpati, S. E., \& Li, S. (2005). Test accommodations for students with disabilities: An analysis of the interaction hypothesis. Review of Educational Research, 75, 457-490.

Stiggins, R. J., \& Conklin, N. F. (1992). In teachers' hands: Investigating the practice of classroom assessment. Albany, NY: SUNY Press.

Stobart, G. (2008). Testing times: The uses and abuses of assessment. Abingdon: Routledge.

United Nations (UN) General Assembly. (2007). Convention on the Rights of Persons with Disabilities. resolution/adopted by the General Assembly, 24 January 2007, A/RES/61/106. Retrieved from http://www.unhcr.org/refworld/docid/45f973632.html

United Nations (UN) General Assembly. (1989). Convention on the Rights of the Child. United Nations, Treaty Series, 1577, 3. Retrieved from http://www.unhcr.org/refworld/docid/ 3ae6b38f0.html

Walker v. State of Victoria. (2011). FCA 258 (Tracey J, Federal Court of Australia, 23 March 2011) (2011).

Webster, A. A., \& Carter, M. (2010). Adaptation of an interview-based protocol to examine close relationships between children with developmental disabilities and peers. Journal of the Australasian Association of Special Education, 34, 79-94.

Webster, A. A., \& Carter, M. (2010). Characteristics of the closest relationships between children with developmental disabilities and peers in inclusive settings. Journal of the Australasian Association of Special Education, 34, 61-78.

Whitburn, B. J. (2011). Vision impaiment and inclusion: A study of secondary school students. (Unpublished masters' thesis). Griffith University, Brisbane, Australia.

Zuriff, G. E. (2000). Extra examination time for students with learning disabilities: An examination of the maximum potential thesis. Applied Measurement in Education, 13, 99-107. 